\title{
MICROMACHINED VARIABLE CAPACITOR WITH WIDE TUNING RANGE
}

\author{
Zhixiong Xiao, Wuyong Peng, R. F. Wolffenbuttel* and K. R. Farmer \\ ${ }^{1}$ New Jersey Institute of Technology, Microelectronics Research Center, \\ 121 Summit Street- Rm 200, Newark, NJ 07102, USA \\ *Delft University of Technology, ITS/Et, DIMES/ Lab. EI, \\ Mekelweg 4, 2628 CD Delft, The Netherlands
}

\begin{abstract}
In this paper, ultra-thin silicon wafers, SU-8 bonding and DRIE technology have been combined for the fabrication of a folded spring, dual electrostatic drive, vertical plate variable capacitor device with displacement limiting bumpers. The SU-8 bonding replaces the use of expensive SOI wafers and enables a more flexible design. The thick SU- 8 also decreases the parasitic substrate capacitance. Due to the presence of the bumpers, our variable capacitor has two tuning voltage regimes: first a parabolic region that achieves roughly a $290 \%$ tuning range, then a linear region that achieves an additional $310 \%$, making the total tuning range about $600 \%$, possibly the largest range reported in the literature to date.
\end{abstract}

\section{INTRODUCTION}

Electronically tunable capacitors are key elements in communications circuits such as voltage controlled oscillators and tunable capacitor filters. Numerous papers address variable capacitors[1-16]. In an integrated circuit design, a variable capacitor is usually realized with a reversed $p-n$ junction, which can give a 335\% tuning range[13]. However, the silicon p-n junction usually has large series resistance plus parasitic capacitance to the substrate. The variable capacitors manufactured with micromachining technology can accommodate large voltage swings so that the phase noise can be improved by allowing a large voltage swing across an LC circuit. This is normally not possible with $\mathrm{p}-\mathrm{n}$ junction capacitors, where the designer must ensure that the junction does not become forward-biased over the tuning voltage range. Additionally, micro-mechanical capacitors are not expected to respond to microwave frequencies, which are normally 10,000 times higher than their mechanical resonant frequencies. Hence these devices are not expected to produce a large amount of harmonic distortion.

For electrostatic drive variable capacitors fabricated using micromachining processes, Yao, et al., [13] have reported a capacitor with a tuning range of $200 \%$ based on lateral comb structures on an SOI substrate. Feng, et al., [16] have used a thermal actuator in their variable capacitor and achieved a tuning range of $270 \%$. In this paper, ultra-thin silicon wafers, SU-8 bonding and DRIE technology have been combined for the fabrication of a folded spring, dual electrostatic drive, vertical plate device with displacement limiting bumpers. The total tuning range of this variable capacitor is about $600 \%$.

\section{DESIGN AND THEORY}

Figure 1 shows a simplified electrical/mechanical schematic of our variable capacitor and LC drive circuit. The device consists of sets of fixed and movable vertical plates, forming separate drive and sense capacitors. Figure 2 shows several microscope images of the fabricated device. In Fig. 2a, two separate drive capacitors are

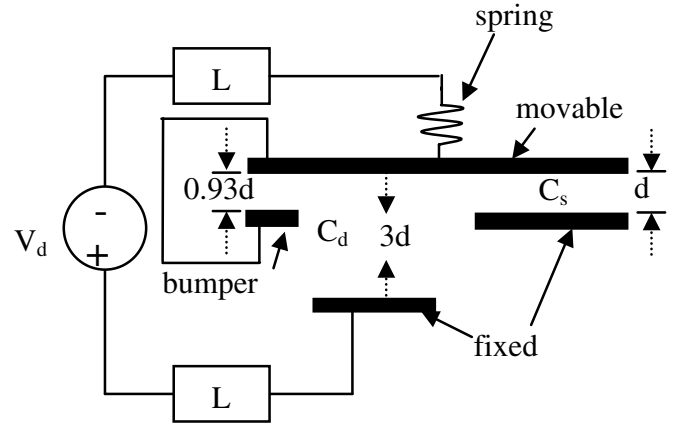

Figure 1. Electrical/mechanical schematic of micromachined variable capacitor and $L C$ drive circuit. $C_{d}$, the drive capacitor, has an electrode spacing that is three times that of $C_{s}$, the sense capacitor. $L$ is about $0.1 \mathrm{mH}$.
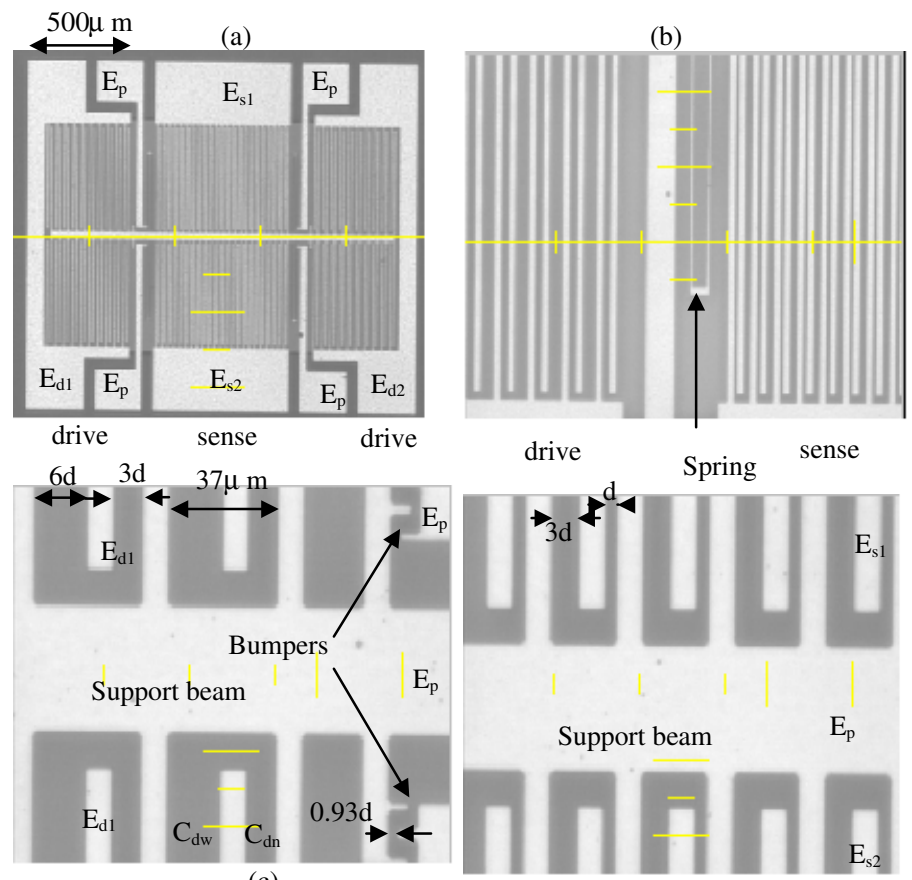

(c)

(d)

Figure 2. (a) Top view of fabricated device. The drive voltage is applied between the common electrode $E_{p}$ and the drive electrodes $E_{d 1}$ and $E_{d 2}$. The capacitance is sensed between $E_{s}$ (shorted $E_{s 1}$ and $E_{s 2}$ ) and the common electrode $E_{p}$. The movable fingers are mounted to a center support beam and connected to the $E_{p}$ electrodes by $4 \mu \mathrm{m}$ wide, $730 \mu \mathrm{m}$ long, $29.5 \mu \mathrm{m}$ thick springs. (b) Close up image showing a portion of the folded spring. (c) Close up image of drive capacitor showing placement of movable fingers with smallest asymmetric electrode spacing $3 d=9 \mu \mathrm{m}$ and bumper spacing nominally $0.93 d=2.8 \mu \mathrm{m}$. The bumpers are always at the same potential. (d) Close up image of sense capacitor showing smallest electrode spacing $d=3.0 \mu \mathrm{m}$. 


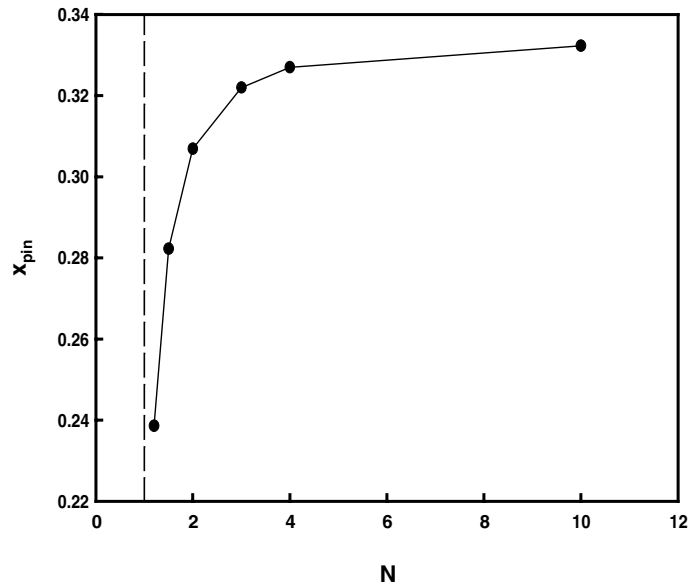

Figure 3. Fractional displacement at pull-in, $x_{\text {pin }}$, versus drive electrode wide to narrow gap spacing ratio, $N>1$.

placed symmetrically on the ends of the structure, and the sense capacitor occupies the center region. The sense and drive capacitors share a common electrode $E_{p}$, which is connected through four folded springs to a movable support beam with attached fingers. A portion of a folded spring is shown in Fig. 2b. As shown in Figs. $2 c$ and $2 d, C_{d}$ and $C_{s}$ actually consist of wide and narrow air gap capacitances. In both cases, the net capacitance
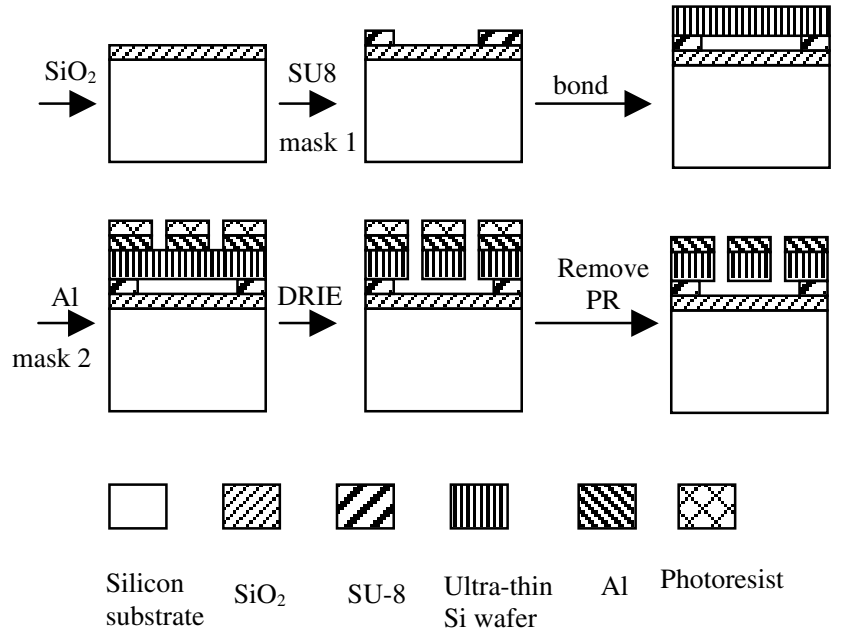

Figure 4. Two mask process schematic for micromachined variable capacitor

is strongly dominated by the narrow gap behavior. The narrow drive gap spacing is designed to be three times that of the narrow sense gap so that a maximum sense electrode displacement can be achieved at the lowest possible applied voltage without causing drive electrode pull-in. The $2.8 \mu \mathrm{m}$ long bumpers in Fig. $2 \mathrm{c}$, which are always at the same potential, limit the maximum displacement to less than the full $3 \mu \mathrm{m}$ sense gap distance. Before the electrode $\mathrm{E}_{\mathrm{p}}$ contacts the bumpers, the capacitance increases parabolically with increasing applied voltage. After contact, the capacitance increases approximately linearly. This is similar to a previous report in [17] where curved electrode actuators were used to extend the travel range.

The voltage for transition from parabolic to linear behavior can be estimated analytically by calculating the drive electrode pull-in voltage, $\mathrm{V}_{\text {pin }}$. Balancing the electrostatic and mechanical forces before pull-in gives

$$
\frac{\varepsilon_{0} V^{2} A}{2\left(d_{0}-\Delta d\right)^{2}}-\frac{\varepsilon_{0} V^{2} A}{2\left(N d_{0}+\Delta d\right)^{2}}=k \Delta d
$$

where $\mathrm{N}$ is the wide to narrow gap spacing ratio for the drive electrode, (N.B., $\mathrm{N}>1$ ) and $\Delta \mathrm{d}$ is the displacement. A, $\mathrm{e}_{0}, \mathrm{~V}$ and $\mathrm{k}$ are the capacitor area, permittivity of free space, applied voltage and spring constant, respectively. An expression for the fractional displacement at pull-in, $x=? \mathrm{~d}_{\mathrm{pin}} / \mathrm{d}_{0}$, is found by maximizing equation (1). Thus differentiating (1) with respect to displacement, multiplying by ?d, and subtracting (1), gives

$\frac{1-3 x_{p i n}}{\left(1-x_{p i n}\right)^{3}}-\frac{N+3 x_{p i n}}{\left(N+x_{p i n}\right)^{3}}=0$

where the normalized displacement at pull-in depends only on N. Figure 3 shows a plot of $x_{\text {pin }}$ versus N. Observe that $x_{\text {pin }}$ decreases dramatically as $\mathrm{N}$ approaches 1 . For example, at $\mathrm{N}=2$, $\mathrm{x}_{\mathrm{pin}}=0.3069$. When $\mathrm{N}$ is infinite, $\mathrm{x}_{\mathrm{pin}}=1 / 3$, which is the well known result for a single parallel plate system.

By substituting $\mathrm{x}_{\text {pin }}$ into equation (1), the pull-in voltage can be written as
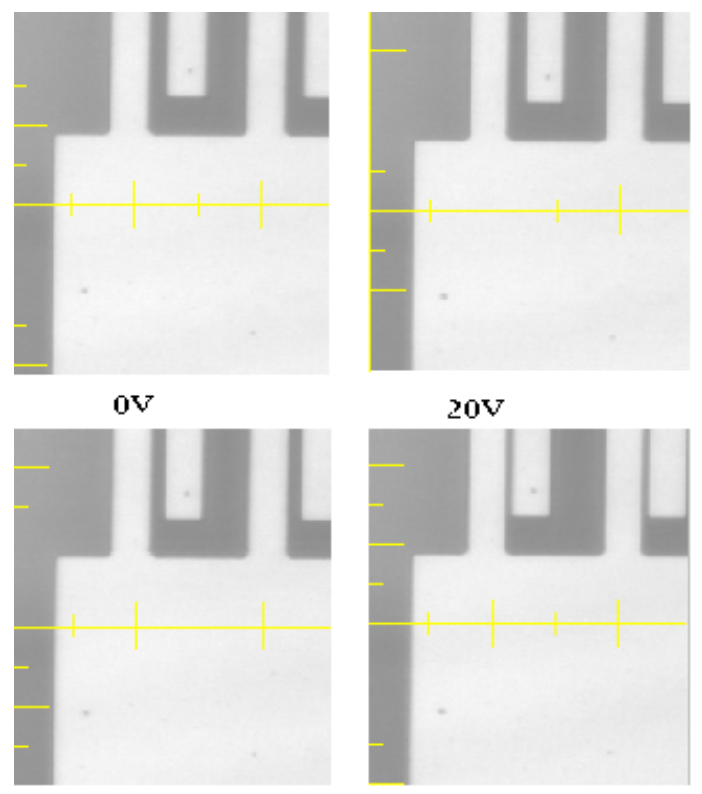

4uV

$57.5 \mathrm{~V}$

Figure 5. A portion of the sense capacitor at various drive voltages

$V_{p \text { in }}=\sqrt{\frac{x_{p i n}}{\frac{1}{\left(1-x_{p i n}\right)^{2}}-\frac{1}{\left(N+x_{p i n}\right)^{2}}} \frac{2 d_{0}^{3} k}{\varepsilon_{0} A}}$

As discussed in the following section, the analytical results can be compared with simulation results obtained using MEMCAD (now COVENTOR) finite element analysis software. Using this tool, the spring constant for our system is estimated to be about 13 $\mathrm{N} / \mathrm{m}$. 


\section{FABRICATION AND RESULTS}

Figure 4 shows the main fabrication steps. The process starts with SU-8 photolithography on an oxidized silicon wafer to form a cavity. The realized cavity depth is about $22 \mu \mathrm{m}$ at $3000 \mathrm{rpm}$. An ultrathin silicon wafer[18] was bonded to the silicon substrate by SU-8 bonding[19] at $105^{\circ} \mathrm{C}$, using an EVI 501 universal bonding system. Aluminum was then sputtered onto the bonded wafer stack, and patterned by $\mathrm{HP}_{3} \mathrm{O}_{4}$ etching at $40^{\circ}$ after photolithography. The devices were released by deep reactive ion etching (DRIE) using the BOSCH process in a Unaxis/PlasmaTherm inductively coupled plasma system. Finally, the photoresist was removed using oxygen plasma etching. The aluminum on the structure, besides allowing good external electrical contact, also decreases the device series resistance, improving its $\mathrm{Q}$ factor.

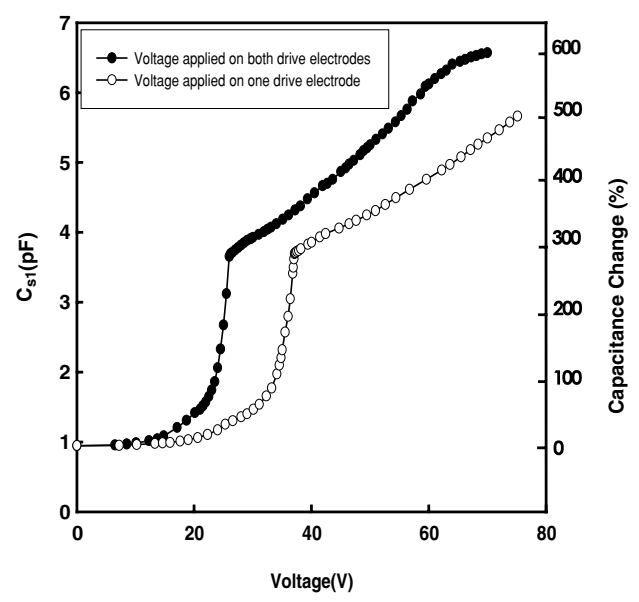

Figure 6. The measured capacitance $C_{s l}$, between $E_{s 1}$ and $E_{p}$ (left axis), and the percentage change in capacitance (right axis) versus voltage

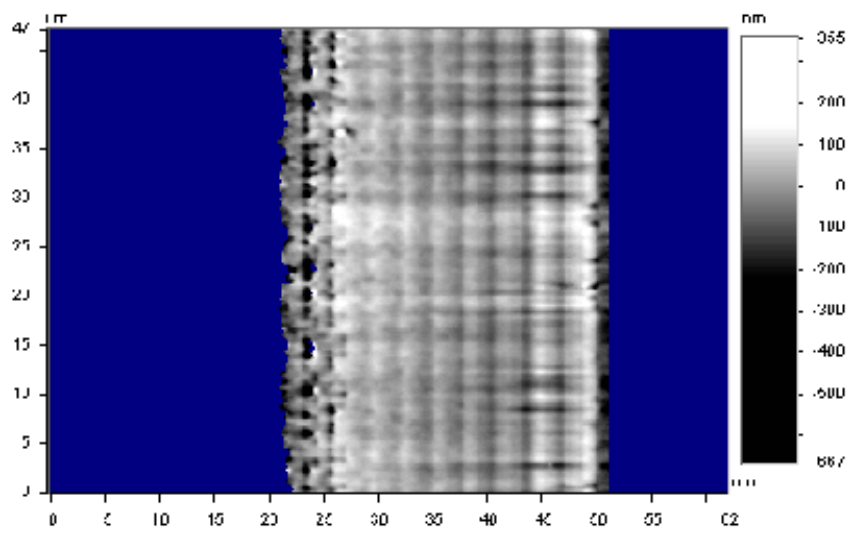

Figure 7. Optical profile of device sidewall after DRIE etching

Figure 5 shows sense capacitor photos at $0 \mathrm{~V}, 20 \mathrm{~V}, 40 \mathrm{~V}$ and $57.5 \mathrm{~V}$ when voltage was applied on only one drive electrode. As expected, the capacitor electrodes move closer when the voltage increases.

Figure 6 shows the measured sense capacitance value $C_{s}$ between one sense electrode $\mathrm{E}_{\mathrm{s} 1}$, and the common electrode, $\mathrm{E}_{\mathrm{p}}$. The figure also shows the percentage change in capacitance. The capacitance is measured using an HP 4284A precision LCR meter. The amplitude and frequency of the testing signal were $5 \mathrm{mV}$ and $1 \mathrm{MHz}$, respectively. When voltage is applied on both drive electrodes, the capacitance parabolically increases from $0.945 \mathrm{pF}$ at $0 \mathrm{~V}$ to $3.657 \mathrm{pF}$ at $26 \mathrm{~V}$, and then increases nearly linearly to $6.57 \mathrm{pF}$ at $70 \mathrm{~V}$. This corresponds to tuning ranges of $287 \%$ at $26 \mathrm{~V}$ and $595 \%$ at $70 \mathrm{~V}$. When voltage is applied on one drive electrode, the capacitance increases parabolically from $0.945 \mathrm{pF}$ at $0 \mathrm{~V}$ to $3.696 \mathrm{pF}$ at $37.1 \mathrm{~V}$, and then nearly linearly to $5.55 \mathrm{pF}$ at $75.1 \mathrm{~V}$. This corresponds to tuning ranges of $290 \%$ at $37.1 \mathrm{~V}$ and $497.5 \%$ at $75.1 \mathrm{~V}$. For each measurement, the results are reproducible and without discernable DC hysteresis. In addition, the final displacement appears only to be limited by dielectric breakdown, which exceeds $80 \mathrm{~V}$ for these devices in air. Figure 7 shows the capacitor sidewall image using a VEECO NT3300 optical profilometer. It shows that the ultrathin silicon wafer is approximately $29.5 \mu \mathrm{m}$ thick. In addition, the image reveals the capacitor surface microroughness induced by the Bosch etching process. The RMS roughness is about $71 \mathrm{~nm}$.

Table 1 provides a comparison of the measured transition voltages to analytical and COVENTOR 2001 pull-in simulation results. For completeness, COVENTOR simulation parameters are also given in the table. Good agreement is found for the two cases, when voltage is applied either to only one or to both drive electrodes. Note that the measured transition voltage is slightly higher than the analytical and simulation results, but this can easily be attributed to non-parallel electrodes or other effects neglected in the theory. The possibility of non-parallel electrodes (i.e., a few degree DRIE sidewall slope) is suggested by the observation that the drive electrodes never seen to make full contact at the top surface of the device. While we have achieved a wide tuning range in these capacitors, we note that even with the addition of aluminum, the measured $\mathrm{Q}$ factor is only $\sim 100$ at $1 \mathrm{MHz}$. We attribute this result to the use of relatively high resistivity, 1-10 Ocm, ultra-thin silicon wafers. We are currently fabricating improved devices using heavily doped silicon, as well as softer springs and improved drive electrodes to lower the drive voltage.

Table 1. Comparison of measured transition voltage to analytical and COVENTOR simulation results

\begin{tabular}{|c|c|c|c|}
\hline & $\begin{array}{l}\text { Measured } \\
\text { transition } \\
\text { voltage }\end{array}$ & $\begin{array}{l}\text { Calculated } \\
\text { pull-in } \\
\text { voltage }\end{array}$ & $\begin{array}{l}\text { COVENTOR } \\
\text { pull-in voltage }\end{array}$ \\
\hline \multirow{2}{*}{$\begin{array}{l}\text { Voltage on } \\
\text { one electrode }\end{array}$} & \multirow[t]{2}{*}{$37.1 \mathrm{~V}$} & \multirow[t]{2}{*}{$35.0 \mathrm{~V}$} & $34.25 \mathrm{~V}$ \\
\hline & & & $\begin{array}{l}27 \text { node element } \\
\text { for meshing } \\
20583 \text { total nodes } \\
\text { convergence } \\
\text { ratio }=5 \times 10^{-3}\end{array}$ \\
\hline \multirow{2}{*}{$\begin{array}{l}\text { Voltage on } \\
\text { both } \\
\text { electrodes }\end{array}$} & \multirow[t]{2}{*}{$26.0 \mathrm{~V}$} & \multirow[t]{2}{*}{$24.75 \mathrm{~V}$} & $23.91 \mathrm{~V}$ \\
\hline & & & $\begin{array}{l}27 \text { node element } \\
\text { for meshing } \\
22869 \text { total nodes } \\
\text { convergence } \\
\text { ratio }=5 \times 10^{-3}\end{array}$ \\
\hline
\end{tabular}




\section{CONCLUSIONS}

In summary, combining ultra-thin silicon wafers, SU-8 bonding and DRIE, we have designed and fabricated a micromachined variable capacitor that exhibits two tuning regimes, parabolic and linear, and has achieved roughly a $600 \%$ tuning range.

\section{ACKNOWLEDGEMENT}

This work was supported through the National Science Foundation, awards ECS-9624798 and DMR-9871272, and the New Jersey Commission on Science and Technology through the NJ MEMS Initiative.

\section{REFERENCES}

1. R. S. Muller and T. I. Kamins, "Device electronics for integrated circuits", John Wiley \& Sons Inc., 1977.

2. F. Svelto, P. Erratico, S. Manzini, and R. Castello, "A metaloxide-semiconductor varactor", IEEE Electron Device Letters, 20, 164-166(1999).

3. C. L. Goldsmith, A. Malczewski, Z. J. Yao, S. Chen, J. Ehmke, and D. H. Hinzel, "RF MEMS variable capacitors for tunable filters", International Journal of RF and Microwave Aided Engineering, 9(4), 362-374(1999).

4. D. J. Young, V. Malba, J. J. Ou, A. F. Bernhardt, and B. E. Boser, "Monolithic high-performance three-dimensional coil inductors for wireless communication application", Tech. Digest, International Electron Devices Meeting, 1997, pp. 6770.

5. D. J. Young, V. Malba, J. T. Ou, A. F. Bernhardt, and B. E. Boser, "A low-noise RF voltage-controlled oscillator using on-chip high $Q$ three-dimensional coil inductor and micromachined variable capacitor", Technical Digest of Solid-State Sensor and Actuator Workshop, Hilton Head Isl., SC(1998), pp. 128-131.

6. D. J. Young, and W. E. Boser, “A micromachined variable capacitor for monolithic low-noise VCOs in cellular phone application", Technical Digest of Solid-State Sensor and Actuator Workshop, Hilton Head Isl., SC(1996), pp. 86-89.

7. M. Steyaert, and J. Craninckx, " $1.1 \mathrm{GHz}$ oscillator using bondwire inductance", Electronics Letters, 30, 244245(1994).
8. D. J. Young, J. L. Tham, and B. E. Boser, "A micromachinebased low phase-noise $\mathrm{GHz}$ voltage-controlled oscillator for wireless communications", Proceeding of 10th Solid-State Sensor and Actuators, Sendai, Japan(1999), pp. 1386-1389.

9. A. Dec, and K. Suyama, "Micromachined varactor with wide tuning range", Electronics Letters, 33, 922-924(1997).

10. A. Dec, and K. Suyama, "A $1.9 \mathrm{GHz}$ micromachined-based low phase noise CMOS VCO", Proceeding of $46^{\text {th }} I E E E$ International Solid-State Circuits Conference, San Francisco Marriott. (1999), pp. 80-81.

11. E. S. Hung and S. D. Senturia, "Tunable capacitors with programmable capacitance-voltage characteristic", Technical Digest of 1998 Solid-State Sensor and Actuator Workshop, Hilton Head Isl., SC(1998), pp. 292-295.

12. M. Husák, "One-chip integrated resonance circuit with a capacitive pressure sensor", J. Micromech. Microeng. 7, 173178 (1997).

13. J Jason Yao, "RF MEMS from a device perspective", $J$. Micromech. Microeng. 10, R9-R38(2000).

14. A. Dec, and K. Suyama, "Microwave MEMS-Based VoltageControlled Oscillators", IEEE Transactions on Microwave Theory and Techniques, 48, 1943-1949(2000).

15. J. Zou, C. Liu, J. Schutt-Aine, J. Chen, and S.-M. Kang, "Development of Wide Tuning Range MEMS Tunable Capacitor for Wireless Communication Systems", Tech. Digest, International Electron Devices Meeting, San Francisco, CA(2000), pp. 403-406.

16. Z. Feng, H. Zhang, W. Zhang, B. Su, K. Gupta, V. Bright, Y. Lee, "MEMS-based variable capacitor for millimeter-wave applications", Tech. Digest, Solid-State sensors and Actuators Workshop, Hilton Head Island, SC(2000), pp. 255-258.

17. R. Legtenberg, J. Gilbert, S. D. Senturia, and M. Elwenspoek, "Electrostatic curved electrode actuators", IEEE J. of Microelecromechanical Systems, 6, 257(1997).

18. Ultrathin silicon wafers are available from Virginia Semiconductor, Inc., Fredericksburg, VA.

19. S. K. Sampath, L. St.Clair, Xingtao Wu, D. V. Ivanov, Q. Wang, C. Ghosh and K. R. Farmer, "Rapid MEMS Prototyping using SU-8, Wafer Bonding and Deep Reactive Ion Etching," Proceedings of the $14^{\text {th }}$ Biennial University/Government/Industry Microelectronics Symposium, Richmond, VA, 6/18-20/ 2001, p. 158. 